\title{
PELATIHAN MICROSOFT WORD UNTUK GURU SD NEGERI 6 PEGUYANGAN KECAMATAN DENPASAR UTARA
}

\author{
Ni Wayan Suardiati Putri \\ STMIK STIKOM Indonesia, Denpasar, Indonesia \\ e-mail: suardiatiputri@stiki-indonesia.ac.id \\ Ni Kadek Suryati \\ STMIK STIKOM Indonesia, Denpasar, Indonesia \\ e-mail: kadeksuryati8@gmail.com \\ Evi Dwi Krisna \\ STMIK STIKOM Indonesia, Denpasar, Indonesia \\ e-mail: evidwikrisna@yahoo.co.id \\ Ketut Sepdyana Kartini \\ STMIK STIKOM Indonesia, Denpasar, Indonesia \\ e-mail: sepdyana27@gmail.com
}

\begin{abstract}
PKM activities at SD Negeri 6 Peguyangan Utara Denpasar, held on Tuesday-Friday, 3-6 September 2019. PKM activities are carried out on teachers at SD Negeri 6 Peguyangan Utara Denpasar by providing training in the use of Microsoft Word. The training material provided includes how to make lesson plans and report cards on the 13 student curriculum. The training method used is practicum conducted in the classroom using a laptop. From the results of the assessment that has been done, the level of understanding of the participants was obtained from the training material provided based on the pre-test and post-test assessments. The assessment results show that there was an increase in participants' understanding before and after the training. Before attending Microsoft Word training, participants' understanding of the material was $57.99 \%$, where after attending the training, the participant's understanding increased to $85.42 \%$. This shows that the training that has been carried out in PKM activities at SD Negeri 6 Peguyangan, Denpasar Utara, is able to increase participants' understanding of Microsoft Word material.
\end{abstract}

Keywords - Community dedication, Microsoft Word, Training

\section{PENDAHULUAN}

$\mathrm{T}$ eknologi informasi memiliki perkembangan yang sangat pesat dan meliputi berbagai bidang (Patmanthara, 2010). Bidang pendidikan merupakan salah satu bidang yang dipengaruhi oleh teknologi informasi. Baik dalam proses pembelajaran formal di sekolah maupun nonformal berupa pelatihan di luar sekolah. Peran kampus STMIK STIKOM Indonesia melalui Program Studi Teknik Informatika 
memiliki peran penting dalam meningkatkan proses belajar mengajar dengan pemanfaatan teknologi informasi. Hal ini sejalan dengan visi dan misi dari Program Studi Teknik Informatika STMIK STIKOM Indonesia.Sekolah Dasar bertujuan untuk mempersiapkan anak dalam memasuki era pendidikan sekolah menengah pertama dan mengembangkan kepribadian anak agar mampu bersosialisasi dengan lingkungan keluarga ataupun masyarakat. Dalam pelaksanaan kegiatan belajar mengajar, pemanfaatan teknologi informasi oleh guru menjadi hal yang penting mengingat kemudahan dalam memperoleh materi dan model pembelajaran yang dapat diterapkan ke anak didik. Guru harus mampu mempersiapkan diri terhadap perubahan jaman dan perkembangan teknologi (Ambalegin \& Suhardianto, 2020). Disamping itu kegiatan administrasi disekolah dan sosialisasi tentang kegiatan sekolah juga perlu melibatkan bantuan teknologi informasi agar pekerjaan menjadi lebih efektif dan efisien. SD Negeri 6 Peguyangan adalah sebuah sekolah dasar yang berlokasi di Desa Peguyangan Kecamatan Denpasar Utara Provinsi Bali.

Dari hasil wawancara selanjutnya dengan kepala sekolah SD Negeri 6 Peguyangan, sebagian besar para guru masih sedikit mengenal dan menguasai materi Microsoft Word sehingga mengalami kesulitan dalam mempersiapkan/menyusun materi pelajaran, RPP, dan administrasi sekolah. Berdasarkan latar belakang di atas, dapat dirumuskan permasalahan yaitu Guru guru di SD Negeri 6 Peguyangan masih sedikit yang memiliki keterampilan/kemampuan dalam menggunakan aplikasi Microsoft Word terutama dalam membantu proses belajar mengajar maupun dalam mempersiapkan materi ajar.

Solusi kegiatan pengabdian masyarakat ini diharapkan mampu menjadi solusi atas kendala yang dihadapi di SD Negeri 6 Peguyangan Kecamatan Denpasar Utara, khususnya terkait dengan pemanfaatan teknologi informasi dan mendukung kegiatan belajar dan administrasi sekolah. Solusi yang dapat ditawarkan untuk menangani permasalah yang dialami oleh SD Negeri 6 Peguyangan adalah kegiatan dengan sentuhan ipteks, yaitu: Pelatihan Miscrosoft Word. Kegiatan pengabdian Microsoft Word juga pernah dilakukan oleh (Rianto \& Wardana, 2019), (Pratiwi, 2018), (Ajie, 2019), (Sormin, Sahara, \& Agustina, 2018), (Kurniwan, Alamsyah, \& Hapsari, 2019), dan (Putu, Santiari, \& Rahayuda, 2018). Manfaat yang diperoleh guru-guru SD dari pelaksanaan kegiatan pokok diatas adalah Guru-guru SD Negeri 6 Peguyangan mampu menggunakan Miscosoft Word dalam menyusun perangkat pembelajaran di sekolah dan mengelola rapor siswa. Tujuan dari kegiatan pengabdian ini adalah meningkatkan kemampuan guru-guru SD Negeri 6 Peguyangan, dalam menggunakan Microsoft Word untuk kebutuhan penyusunan perangkat pembelajaran di sekolah.

\section{METODE}

Pelaksanaan kegiatan pengabdian masyarakat meliputi beberapa kegiatan yaitu pengumpulan data, indentifikasi masalah, analisis kebutuhan materi pelatihan, perancangan dan penyusunan modul pelatihan, pelaksanaan pelatihan, dan dokumentasi kegiatan dan laporan. Alur pelaksanaan kegiatan pengabdian masyarakat disajikan pada gambar dibawah ini: 


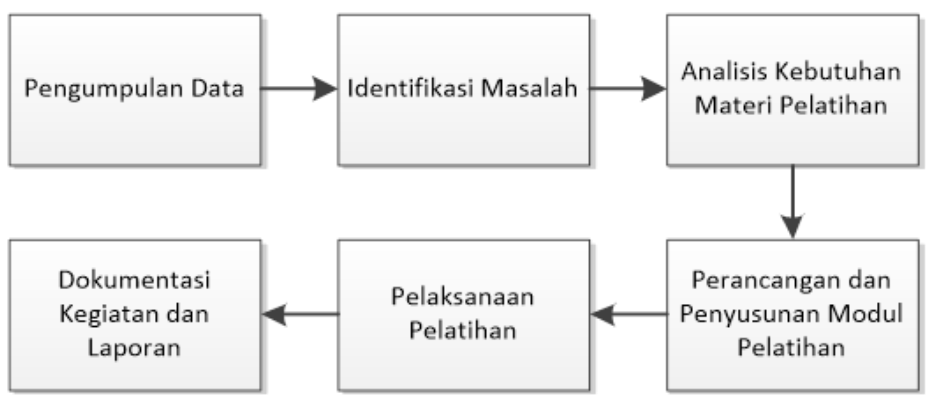

Gambar 1 Alur Pelaksanaan Kegiatan pengabdian masyarakat

Alur pelaksanaan kegiatan pengabdian masyarakat diatas akan dijelaskan secara lebih terperinci pada subbab di bawah ini.

\subsection{Pengumpulan Data}

Tahapan pertama dalam kegiatan pengabdian masyarakat ini adalah pengumpulan data. Kegiatan ini bertujuan untuk mengetahui kondisi di SD Negeri 6 Peguyangan Kecamatan Denpasar Utara. Berdasarkan hasil wawancara dan observasi yang dilakukan dengan beberapa guru SD Negeri 6 Peguyangan di Denpasar Utara, diketahui bahwa penguasaan Teknologi Informasi guru-guru SD Negeri 6 Peguyangan masih rendah. Hal ini dapat dilihat dari sedikitnya guru-guru menggunakan/memanfaatkan teknologi informasi dalam proses kegiatan sekolah. Kurangnya kemampuan guru dalama memanfaatkan komputer dalam pengelolaan administrasi sekolah atau pembuatan perangkat pembelajaran.

\subsection{Identifikasi Masalah}

Setelah dilakukan pengumpulan data selanjutnya dilaksanakan identifikasi masalah. Identifikasi masalah dilakukan untuk mengetahui masalah yang dihadapi oleh SD Negeri 6 Peguyangan Kecamatan Denpasar Utara dalam pemanfaatan teknologi informasi. Masih kurangnya penguasaan komputer dalam pembuatan Rencana Pelaksanaan Pembelajaran (RPP), perangkat pembeljaran sekolah, materi ajar dan administrasi sekolah.

\subsection{Analisis Kebutuhan Materi Pelatihan}

Berdasarkan identifikasi masalah yang dilakukan, maka materi yang dibutuhkan dalam pemanfaatan teknologi informasi di SD Negeri 6 Peguyangan Kecamatan Denpasar Utara, adalah Microsoft Word. Pelatihan materi Microsoft Word bertujuan untuk memberikan pengetahuan kepada guru tentang pengelolaan dokumen, RPP, serta terkait dengan administrasi sekolah dan kegiatan belajar mengajar.

\subsection{Perancangan dan Penyusunan Modul Pelatihan}

Untuk mempermudah dalam kegiatan pelatihan maka perlu disusun modul pelatihan Microsoft Word. Modul ini nantinya akan dijadikan sebagai panduan oleh para guru ketika pelatihan sedang berlangsung, ataupun dapat digunakan sebagai bahan belajar secara mandiri ketika kegiatan pengabdian masyarakat telah selesai. Untuk itu maka modul akan disusun secara baik sehingga mudah dipahami dan 
dapat digunakan untuk belajar secara mandiri oleh para guru. Setiap guru yang menjadi peserta pelatihan akan diberikan sebuah modul yang telah dicetak.

\subsection{Pelaksanaan Pelatihan}

Pelaksanaan pelatihan akan dilaksanakan di SD Negeri 6 Peguyangan Kecamatan Denpasar Utara dalam masa waktu kegiatan pengabdian masyarakat ini. Kegiatan akan dilakukan selama 4 hari dengan lama pelatihan 8 jam/hari. Kegiatan akan diikuti oleh 12 guru.

\section{HASIL DAN PEMBAHASAN}

\subsection{Pelaksanaan Kegiatan PKM}

Kegiatan PKM di SD Negeri 6 Peguyangan Denpasar Utara, dilaksanakan pada hari Selasa-Jumat, 3-6 September 2019. Kegiatan PKM dilakukan terhadap guru-guru di SD Negeri 6 Peguyangan Denpasar Utara dengan memberikan pelatihan penggunaan Microsoft word. Materi pelatihan yang diberikan meliputi cara pembuatan RPP berbasis kurikulum 13, dan pembuatan Rapor K13. Kegiatan PKM yang dilakukan mendapat dukungan dari Kepala Sekolah SD Negeri 6 Peguyangan Denpasar Utara. Hal ini dapat dilihat dari antusias beliau membuka pada awal pelaksanaan kegiatan PKM sekaligus ikut dalam kegiatan PKM selama 4 hari.

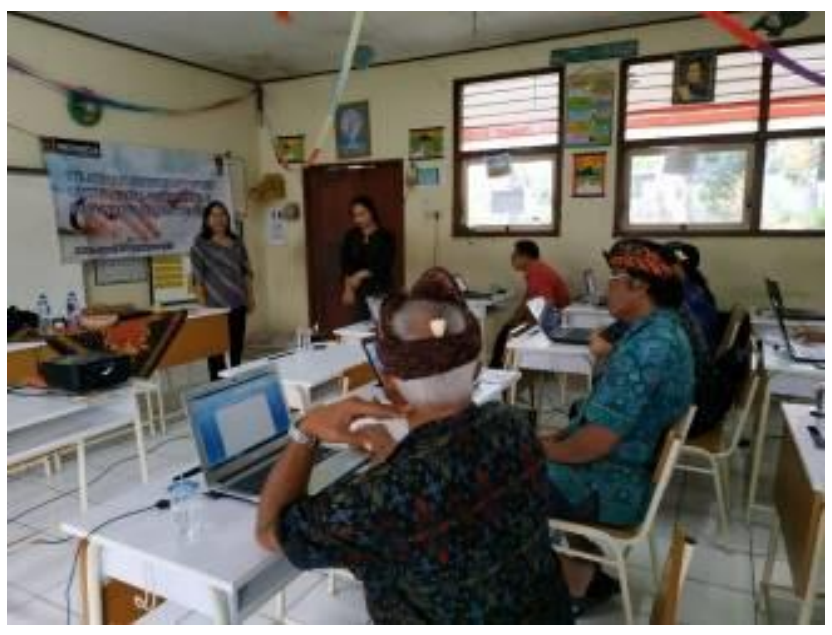

Gambar 2 Sambutan Kepada Sekolah

Gambar 2 merupakan dokumentasi ketika Kepala Sekolah memberikan sambutan saat awal kegiatan PKM yang dihadiri oleh guru-guru SD Negeri 6 Peguyangan Denpasar Utara. Kepala Sekolah sangat mendukung diadakannya kegiatan PKM, mengingat pemanfaatan teknologi komputer khususnya dibidang pendidikan sangat penting untuk dilakukan. Salah satunya adalah dalam administrasi surat-menyurat dan pembuatan perangkat pembelajaran dan pelaksanaan dokumen evaluasi belajar siswa (rapor). Akhir sambutan Kepala Sekolah menyampaikan ucapan terima kasih atas terpilihnya SD Negeri 6 Peguyangan Denpasar Utara sebagai lokasi pelaksanaan kegiatan PKM. Harapannya, materi pelatihan yang diberikan dapat dipahami dan diterapkan oleh 
perserta pelatihan yang dalam hal ini adalah guru-guru SD Negeri 6 Peguyangan Denpasar Utara.

Kegiatan pelatihan berlangsung selama 4hari yaitu pada hari Selasa-Jumat, 36 September 2019, bertempat di ruang kelas SD Negeri 6 Peguyangan Denpasar Utara. Kegiatan diikuti oleh 12 orang guru. Materi pelatihan yang diberikan adalah pemanfaatan Microsoft word, yang dalam hal ini adalah "Pembuatan RPP dan rapor siswa berbasis Kurikulum 2013 (K13)"

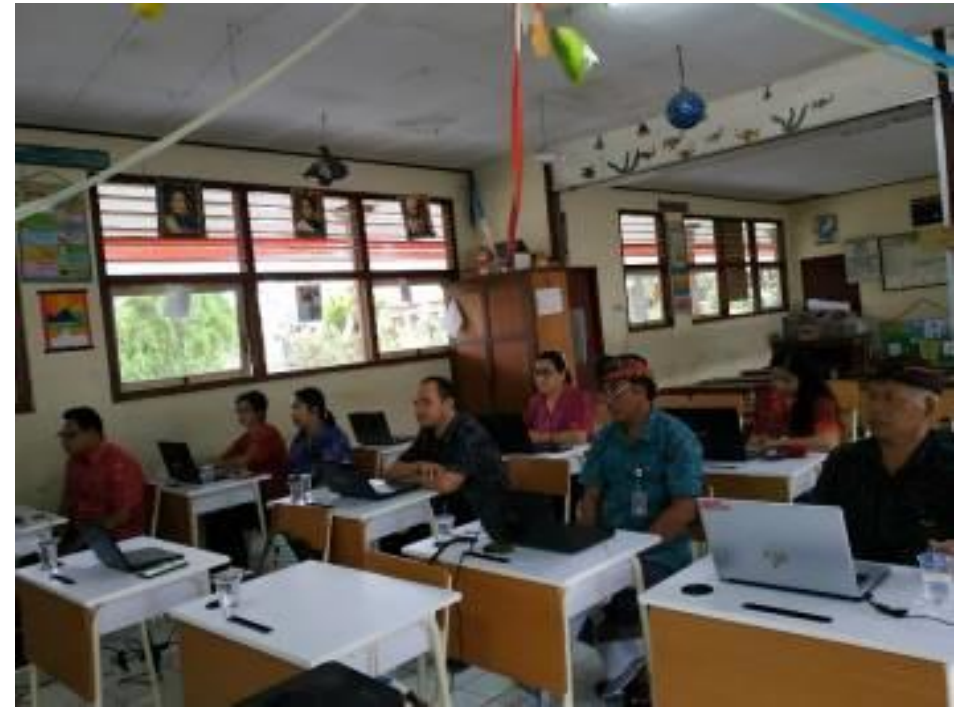

Gambar 3 Guru-guru SD mengikuti pelatihan Miscrosoft Word

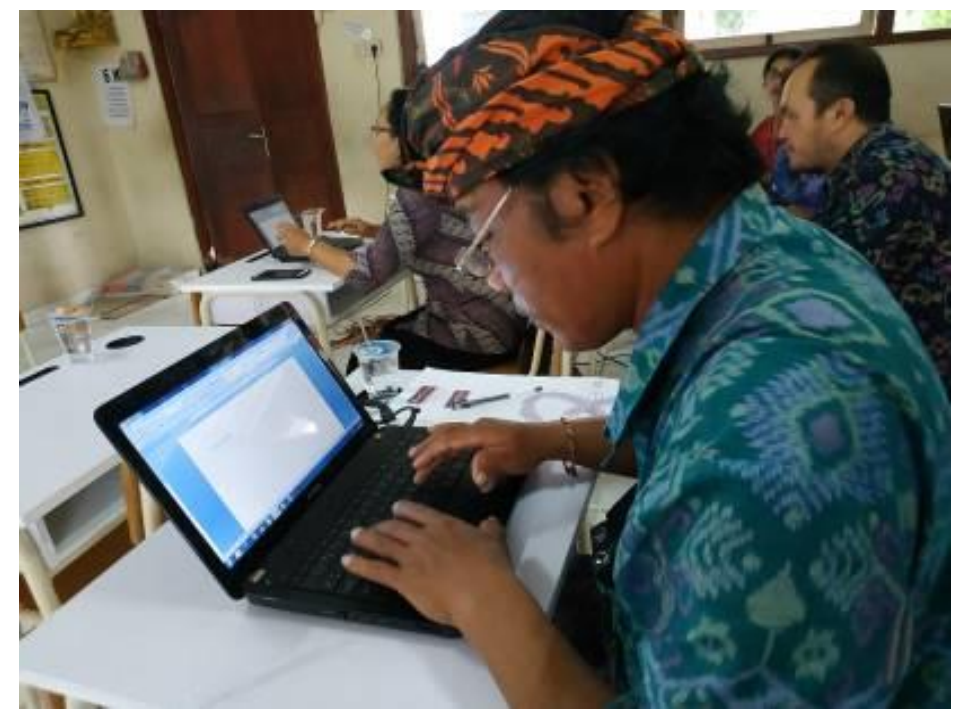

Gambar 4 Guru-guru SD mengikuti pelatihan Miscrosoft Word 


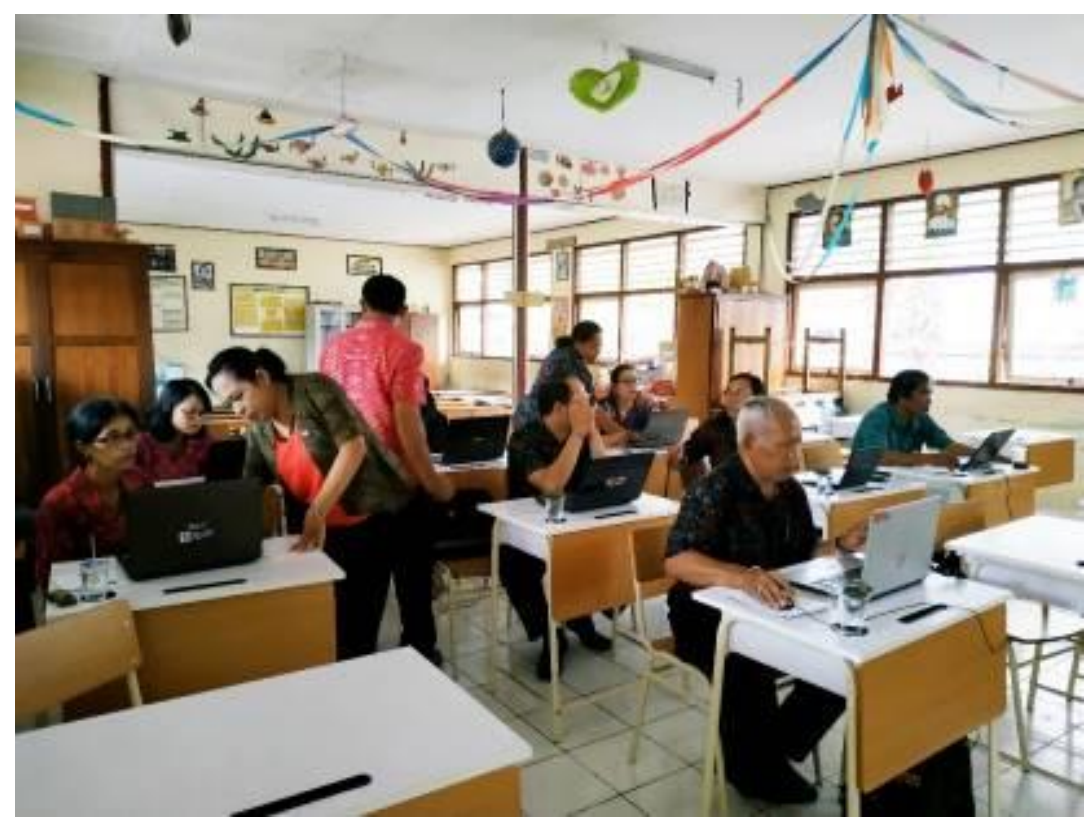

Gambar 5 Pendampingan pelatihan oleh fasilitator

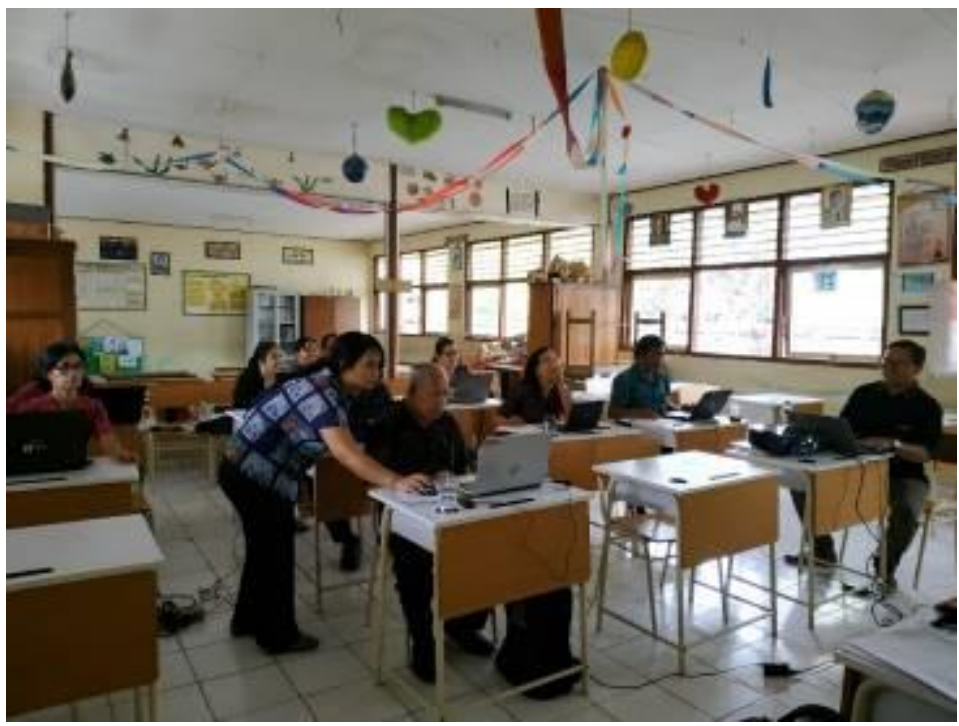

Gambar 6 Fasilitator membantu peserta yang kesulitan mengikuti pelatihan

Gambar 3, Gambar 4, Gambar 5 dan Gambar 6 merupakan dokumentasi selama kegiatan pelatihan berlangsung. Peserta tidak hanya dipandu oleh seorang mentor, namun juga diberikan pendampingan oleh fasilitator. Hal ini dilakukan agar peserta dapat mengikuti pelatihan secara menyeluruh dan tidak sampai ketinggalan. Disamping itu juga memberikan semangat bagi peserta dalam mengikuti pelatihan, 
karena fasilator selalu membantu ketika peserta menghadapi kendala, sehingga permasalahan yang dialami dapat segera diselesaikan.

Peserta sangat antusias mengikuti pelatihan. Hal ini ditunjukkan oleh kehadiran peserta yang selalu tepat waktu dan mengikuti pelatihan sampai selesai. Setiap kendala yang dihadapi peserta selalu aktif bertanya.

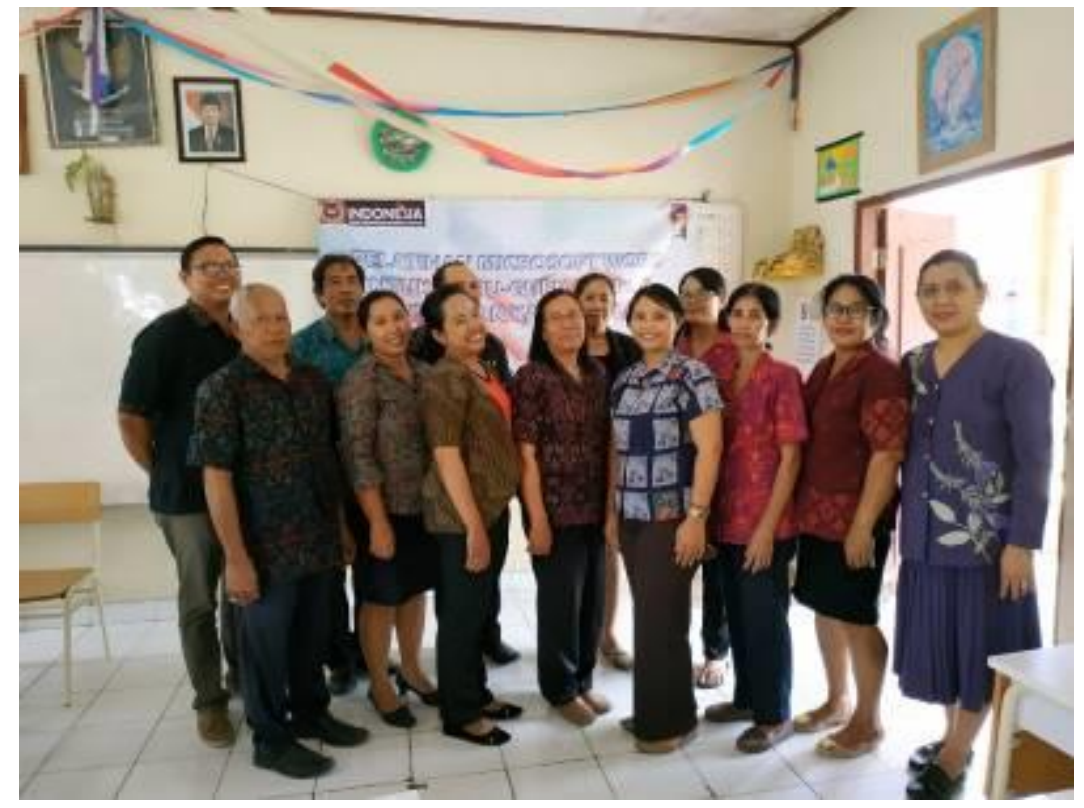

Gambar 7 Peserta pelatihan

\subsection{Hasil Pelaksanaan Kegiatan PKM}

Untuk mengukur keberhasilan kegiatan PKM yang telah dilakukan, maka dibuatlah angket untuk menguji kemampuan peserta sebelum dan sesudah pelatihan dilaksanakan, atau disebut juga pre-test dan post-test. Peserta diberikan soal yang sama untuk membuat RPP berbasis kurikulum 2013. Selama kegiatan berlangsung, fasilitator mencatat kemampuan peserta dalam instrumen penilaian. Baik pre-test ataupun post-test, peserta diberikan soal yang sama dan digunakan instrumen penilaian yang sama.

Pada instrumen penelitian terdapat beberapa komponen yang dinilai yaitu pemahaman terhadap Microsoft Word yang meliputi : cara pengaturan kertas, cara pengaturan huruf, cara pengaturan tabel, cara pengaturan gambar, cara pengaturan penomoran teks, cara pengaturan header/footer, cara pengaturan border, cara penyimpanan dan percetakan dokumen, Berikut merupakan instrumen penilaian yang digunakan saat melakukan pre-test. 


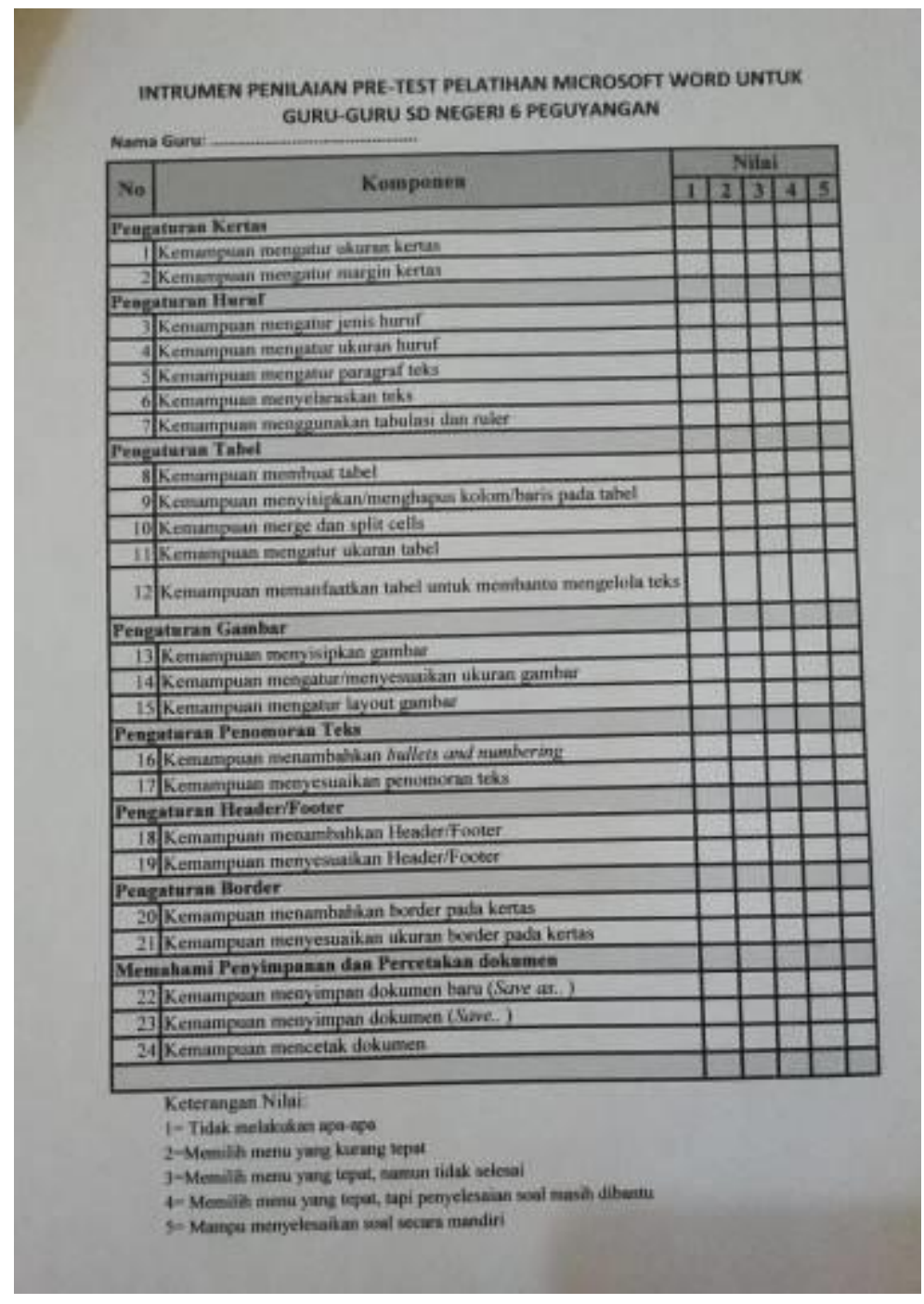

Gambar 8 Instrumen Penilaian Pre-Test 


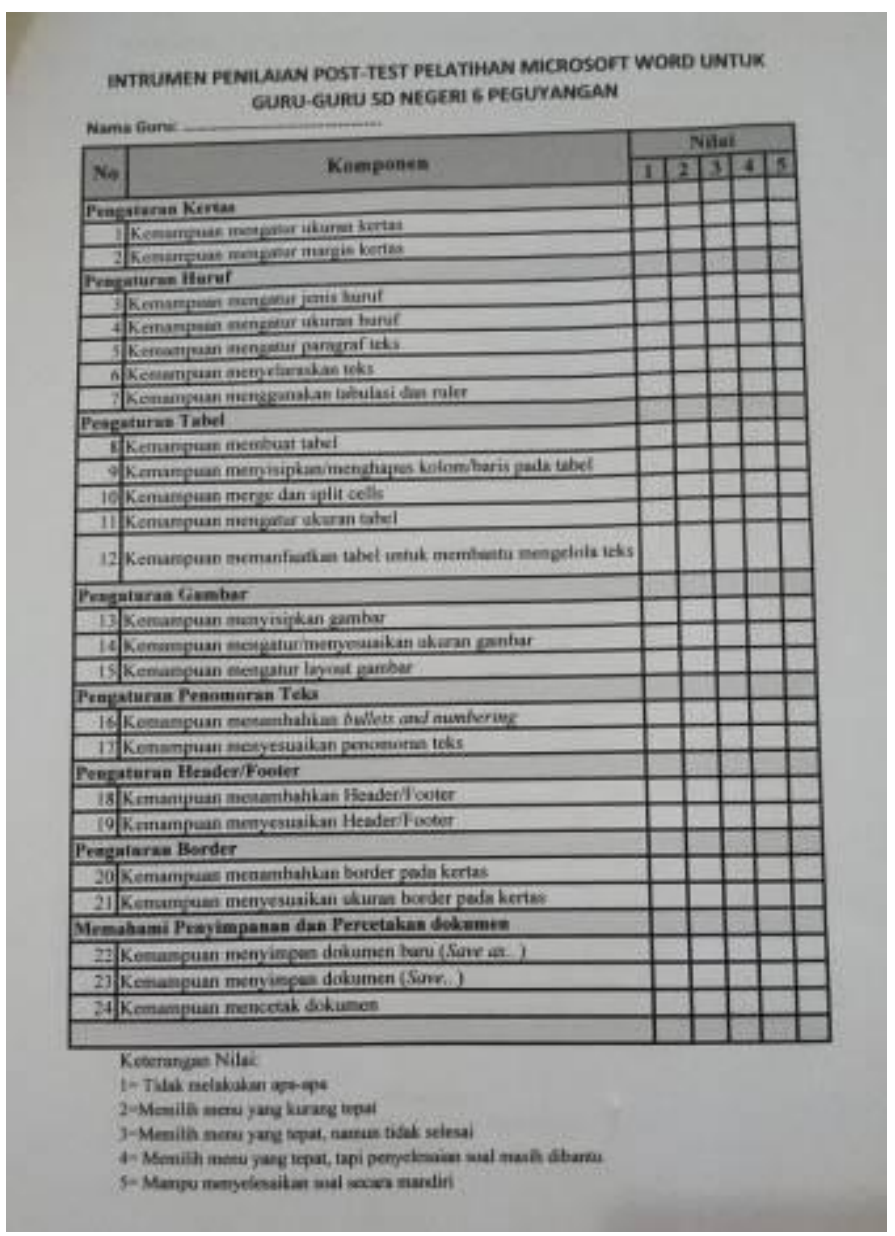

Gambar 9 Instrumen Penilaian Post-Test

Gambar 8 dan Gambar 9 merupakan instrumen penilaian yang digunakan untuk mengukur tingkat keberhasilan dari kegiatan PKM yang telah dilakukan. Komponen penilaian antara pre-test dan post-test yang digunakan adalah sama. Hal ini dilakukan untuk mengukur tingkat pemahaman peserta pelatihan sebelum dan sesudah mengikuti pelatihan.

Dari hasil penilaian yang telah dilakukan, diperoleh tingkat pemahaman peserta terhadap materi pelatihan yang diberikan berdasarkan penilaian pre-test dan post-test sebagai berikut: 


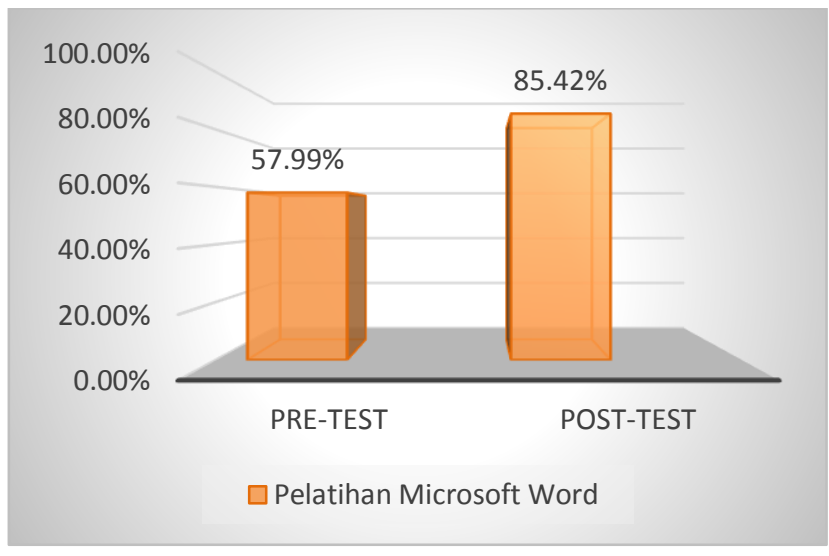

Gambar 10 Grafik tingkat pemahaman peserta terhadap materi pelatihan

Gambar 10 menunjukkan tingkat pemahaman peserta terhadap materi pelatihan yang diberikan. Hasil penilaian menunjukkan bahwa terjadi peningkatan pemahaman peserta sebelum dan sesudah mengikuti pelatihan. Sebelum mengikuti pelatihan Microsoft Word pemahaman peserta terhadap materi adalah 57,99\%, sedangkan setelah mengikuti pelatihan pemahaman peserta meningkat menjadi $85,42 \%$. Ini menunjukkan bahwa pelatihan yang telah dilakukan dalam kegiatan PKM di SD Negeri 6 Peguyangan Denpasar Utara, mampu meningkatkan pemahaman peserta terhadap materi Microsoft Word.

\section{KESIMPULAN}

Dari kegiatan pengabdian masyarakat yang dilakukan, dapat ditarik kesimpulan bahwa pelatihan Microsoft Word kepada guru-guru SD Negeri Peguyangan yang telah dilakukan, mampu meningkatkan kemampuan guru-guru dalam penggunaan Microsoft Word dalam kasus pembuatan RPP dan rapor siswa sebesar $85,42 \%$,

\section{SARAN}

Adapun saran yang dapat diberikan adalah perlu dilakukan pelatihan IT secara berkala untuk melakukan monitoring dan evaluasi terhadap kemampuan guru-guru.

\section{UCAPAN TERIMA KASIH}

Penulis mengucapkan terima kasih kepada LPPM STMIK STIKOM Indonesia yang telah memfasilitasi dalam pelaksanaan pengabdian ini.

\section{DAFTAR PUSTAKA}

Ajie, M. T. (2019). Pelatihan MS. Office Word dan Excel Bagi Perangkat Desa \& Masyarakat Desa Ciaruteun llir Bogor. Terang, 1(1), 86-95. https://doi.org/10.33322/terang.v1i1.209 
Ambalegin, \& Suhardianto. (2020). PENDEKATAN SAINTIFIK DALAM PENGAJARAN BAHASA INGGRIS SMA / SMK. 1(2), 49-58.

Kurniwan, I., Alamsyah, N., \& Hapsari, A. T. (2019). Pelatihan Microsoft Word Dengan TEMA "CRA TE AND EDITING TEKS " Untuk Meningkatkan Kinerja Guru. 02(02), 127-133.

Patmanthara, S. (2010). Analisis Pelaksanaan Uji Online Pada Kompetensi Teknologi Informasi Komunikasi (TIK) Dan Kesiapan Infrastruktur Di SMA Kota Malang. 28-37.

Pratiwi, H. I. (2018). Pelatihan Microsoft Office untuk Karyawan dan Kelompok PKK Kelurahan Sawah Baru Tangerang Selatan. 8-13.

Putu, N., Santiari, L., \& Rahayuda, I. G. S. (2018). Pelatihan MS . WORD Pada SDN 1 GULINGAN. (April), 8-13.

Rianto, R., \& Wardana, A. K. (2019). Pelatihan Microsoft Office Sebagai Upaya Pengembangan dan Peningkatan Kemampuan Penggunaan Aplikasi Pengolah Kata Dan Angka Bagi Guru PAUD Al Muthi'in Yogyakarta. KACANEGARA Jurnal Pengabdian Pada Masyarakat, 2(2), 99-104. https://doi.org/10.28989/kacanegara.v2i2.446

Sormin, M. A., Sahara, N., \& Agustina, L. (2018). Pelatihan Pemanfaatan Perangkat Lunak (Microsoft Office Word, Excel, Power Point) Dalam Kinerja Pengolahan Data Di Pemerintahan Desa Bagikepala Desa Se-Kecamatan Batang Angkola. Martabe: Jurnal Pengabdian Kepada Masyarakat, 1(2), 78. https://doi.org/10.31604/jpm.v1i2.78-82 
